\title{
The effect of theophylline and dibutyryl cyclic AMP on the uptake of radioactive calcium and phosphate ions by boar and human spermatozoa
}

\author{
R. N. Peterson, D. Seyler, Donna Bundman and M. Freund \\ School of Medicine and Department of Physiology, Southern Illinois University at Carbondale, \\ Carbondale, Illinois 62901, U.S.A.
}

\begin{abstract}
Summary. Radioactive calcium uptake by suspensions of washed boar and human spermatozoa was inhibited by the mitochondrial uncoupling agent carbonylcyanidep-trifiuoromethoxy-phenylhydrazone (FCCP). Theophylline + dibutyryl cyclic AMP also inhibited calcium uptake in the presence or absence of FCCP. Uptake of low concentrations of calcium ( $0.1 \mathrm{~mm}$ ) was inhibited by the calcium ionophore A23187, but at high calcium concentrations the ionophore stimulated calcium uptake. These observations are explained in terms of a mechanism for the regulation of calcium uptake in spermatozoa based on competing mitochondrial and plasma membrane pumps. Uptake of ${ }^{32} \mathrm{P}$ was also inhibited. These effects provide evidence that cyclic AMP plays a role in the transport of ions across the plasma membrane of spermatozoa.
\end{abstract}

\section{Introduction}

The mechanism by which cyclic nucleotides increase the motility of mammalian spermatozoa is not known. However, recent evidence suggests that one site of cyclic nucleotide interaction is at the plasma membrane (Peterson \& Freund, 1976; Huacuja, Delgado, Pancardo, Merchant \& Rosado, 1977; Peterson, Bundman \& Freund, 1977). It became of interest, therefore, to determine whether changes in intracellular cyclic AMP levels affect the transport of physiologically important ions. Inorganic phosphate plays an important role in the control of metabolism of most cells, and there is evidence that this ion is taken up by a specific transport system in bull spermatozoa (Babcock, First \& Lardy, 1975). The uptake of calcium ion by bull spermatozoa may also be effected by a specific transport system and there is evidence that this ion is involved in the control of motility (Babcock et al., 1975, 1976).

In the present study we have examined the effects of theophylline and dibutyryl cyclic AMP on the uptake of both calcium and inorganic phosphate in boar and human spermatozoa.

\section{Materials and Methods}

Semen was coliected from adult Yorkshire and Duroc boars by hand and filtered through cheesecloth to remove gel-like solids. The semen was centrifuged three times $(1000 \mathrm{~g})$ to remove seminal plasma and the spermatozoa were resuspended in the following buffer: $0.113 \mathrm{M}-\mathrm{NaCl}$; $0.005 \mathrm{M}-\mathrm{KCl} ; 0.02 \mathrm{M}$-Tris (hydroxymethylamino) methane chloride; $0.005 \mathrm{M}$-glucose and 0.003 M-sodium pyruvate; the $\mathrm{pH}$ was 7.4 at $37^{\circ} \mathrm{C}$. Boar spermatozoa are highly motile in this medium. Human semen was collected from donors, pooled and washed in the buffer described by Peterson \& Freund (1968). 
Motility (percentage motile cells) at room temperature was rated visually by light microscopy by 2 observers and the average of the two values was used. Sperm counts were determined by a haemocytometer method (Freund \& Carol, 1964).

While theophylline alone and dibutyryl cyclic AMP alone stimulated motility, a combination of these agents was more effective and hence was used throughout the study.

Isotope experiments. The uptake of ${ }^{45} \mathrm{CaCl}_{2}$ and ${ }^{32} \mathrm{PO}_{4}$ was measured by the technique of rapid filtration on Millipore glass fibre filters at $30^{\circ} \mathrm{C}$ essentially as described by Babcock et al. (1975) and Peterson \& Freund (1976) but modified as follows. Aliquots $(50-100 \mu l)$ of the sperm suspension, containing the isotope, were removed with automatic pipettes and injected into empty tubes at the same temperature; the tubes were then filled rapidly with $3 \mathrm{ml}$ of wash medium and immediately filtered. The filters were washed 5 times with $3 \mathrm{ml}$ portions of the wash medium. The entire procedure required about $15 \mathrm{sec}$ and resulted in a decrease of the variability in count rates which was observed when samples of the sperm suspensions were directly injected onto the filter and then washed. The specific activity and amount of radioactivity used in each experiment are indicated in the text.

In studies of calcium uptake, the medium used to wash the cells free of unlabelled calcium after incubation contained $10 \mathrm{~mm}$ non-radioactive calcium in addition to the normal buffer constituents. Non-specific (zero time) isotope uptake was estimated by adding the isotope to the sperm suspension and filtering immediately (within $5 \mathrm{sec}$ ). These counts, which averaged about $10 \%$ of the $30 \mathrm{sec}$ uptake count rate, were subtracted from the count rates observed at different times. The uptake of ${ }^{32} \mathrm{PO}_{4}$ was followed in the same way except that $10 \mathrm{~mm}$ non-radioactive phosphate or, in some experiments, $2.5 \mathrm{mM}-\mathrm{HgCl}_{2}$ was used in the wash medium. Sulphydryl groups have been shown to be involved in phosphate transport (Babcock et al., 1975) and $\mathrm{HgCl}_{2}$, which reacts with $\mathrm{SH}$ groups, was used to stop phosphate uptake effectively.

Most assays were carried out at least in triplicate and the Student's $t$ test was used to determine statistical significance.

\section{Materials}

Chemicals of the highest purity available were purchased from the Boehringer Mannheim Company, Sigma Chemical Company and the J. T. Baker Chemical Company. Isotopes were purchased from Amersham-Searle and the New England Nuclear Company. The ionophore A23187 was a gift from the Eli Lily Pharmaceutical Company.

\section{Uptake of radioactive calcium}

\section{Results}

Boar. The effect of various treatments on uptake $0.1 \mathrm{~mm}{ }^{45} \mathrm{CaCl}_{2}$ by washed boar spermatozoa is shown in Table 1. Calcium accumulation was significantly reduced by the

Table 1. Effect of (mean \pm s.e.m. for no. of assays indicated in parentheses) various substances on the uptake of $0.1 \mathrm{mM}^{45} \mathrm{CaCl}_{2}(10 \mu \mathrm{Ci} / \mathrm{ml})$ by boar spermatozoa $\left(3 \times 10^{8} / \mathrm{ml}\right)$

\begin{tabular}{lcc}
\hline \multicolumn{1}{c}{ Addition } & $\begin{array}{c}\text { Uptake } \\
\text { (c.p.m./108 }\end{array}$ & $\begin{array}{c}\text { Inhibition } \\
\text { (\% of control) }\end{array}$ \\
\hline $\begin{array}{l}\text { None (control) } \\
\text { Theophylline }(8 \mathrm{mM})+\end{array}$ & $57276 \pm 3859(9)$ & \\
$\quad$ dibutyryl cyclic AMP $(5 \mathrm{mM})$ & $32078 \pm 852(3)^{*}$ & $56 \cdot 0$ \\
FCCP $(2 \mu \mathrm{M})$ & $12934 \pm 355(3)^{*}$ & $22 \cdot 6$ \\
$\mathrm{~A} 23187(0.1 \mu \mathrm{M})$ & $18662 \pm 787(3)^{*}$ & $32 \cdot 9^{*}$ \\
$\mathrm{~A} 23187(1.0 \mu \mathrm{M})$ & $15901 \pm 537(3)^{*}$ & $27 \cdot 7^{*}$ \\
$\mathrm{LaCl}_{3}(2.5 \mathrm{mM})$ & $9608 \pm 909(3)^{*}$ & $16 \cdot 8^{*}$ \\
\hline
\end{tabular}

* Significantly different from control value, $P<0.001$. 
uncoupling agent carbonylcyanide-p-trifluoromethoxyphenylhydrazone (FCCP) indicating that accumulation depended, at least partly, on energy metabolism. The ionophore A23187, at low and high concentrations, also decreased calcium uptake, as did lanthanum ion which is known to inhibit calcium transport in some cells (Schatzman \& Tschabold, 1971). Theophylline in combination with dibutyryl cyclic AMP significantly decreased calcium accumulation at concentrations that stimulated motility. This effect was also observed at calcium concentrations as high as $1.0 \mathrm{~mm}$ (data not shown), but at the higher calcium concentration A23187 increased calcium entry into the cell by almost $40 \%$. Other experiments showed that when boar spermatozoa were treated with FCCP and then with theophylline + dibutyryl cyclic AMP, calcium uptake was inhibited to a greater extent than was caused by FCCP alone. This suggests that the effects of the theophylline and dibutyryl cyclic AMP reflect an action at the plasma membrane and not on the mitochondrial transport of calcium which should be greatly slowed or abolished by the uncoupling agent.

Man. Previous studies showed that a significant amount of radioactive calcium was bound or taken up by human spermatozoa in the absence of the ionophore A23187, but we assumed that this binding was non-specific, primarily because uptake was rapidly decreased by EGTA and because exogenous calcium failed to increase the fluorescence of membrane bound chlortetracycline (Peterson \& Freund, 1976). The effects of various treatments on the uptake of $0.1 \mathrm{~mm}$ ${ }^{45} \mathrm{CaCl}_{2}$ by washed suspensions of human spermatozoa are shown in Table 2 . The results were very similar to those for boar spermatozoa: FCCP, theophylline + dibutyryl cyclic AMP and A23187 all inhibited uptake. When sperm suspensions were treated with FCCP before adding the isotope, theophylline and dibutyryl cyclic AMP decreased calcium uptake to an extent greater than that caused by FCCP alone (data not shown). The inhibition of calcium uptake at this calcium concentration ordinarily observed in the presence of $A 23187$, was increased by $62 \%$ $(0.2 \mu \mathrm{M}-\mathrm{A} 23187)$ and $45 \%(1.0 \mu \mathrm{M}-\mathrm{A} 23187)$ when theophylline and dibutyryl cyclic AMP were also present in the medium. These results indicate that although mitochondrial uptake is apparently reduced or abolished, elevation of cyclic AMP levels can reduce calcium uptake into the cell, again suggesting an action at the plasma membrane.

Table 2. Effect (mean \pm s.e.m. for 3 determinations) of various substances on the uptake of $0.1 \mathrm{~mm}$ ${ }^{45} \mathrm{CaCl}_{2}(10 \mu \mathrm{Ci} / \mathrm{ml})$ by washed human spermatozoa $\left(2.54 \times 10^{8} / \mathrm{ml}\right.$ in Exp. $1,0.67 \times 10^{8} / \mathrm{ml}$ in Exp. 2)

\begin{tabular}{|c|c|c|c|}
\hline Exp. & Addition & $\begin{array}{c}\text { Uptake } \\
\text { (c.p.m./10 } \\
\text { spermatozoa/3 min) }\end{array}$ & $\begin{array}{c}\text { Inhibition } \\
\text { (\% of control) }\end{array}$ \\
\hline \multirow[t]{2}{*}{1} & $\begin{array}{l}\text { None (control) } \\
\text { FCCP }(2 \text { M) }\end{array}$ & $4771 \pm 62$ & \\
\hline & $\begin{array}{l}\text { FCCP }(2 \mu \mathrm{M})+\text { theophylline }(8 \mathrm{mM})+ \\
\text { dibutyryl cyclic AMP }(5 \mathrm{mM})\end{array}$ & $\begin{array}{l}3114 \pm 64^{*} \\
2100 \pm 168+\ddagger\end{array}$ & $\begin{array}{l}65 \cdot 2 \\
44 \cdot 0\end{array}$ \\
\hline \multirow[t]{2}{*}{2} & None & $3272 \pm 189$ & \\
\hline & $\begin{array}{l}\text { Theophylline }(8 \mathrm{~mm})+ \\
\text { dibutyryl cyclic AMP }(5 \mathrm{~mm})\end{array}$ & $1115 \pm 542 \dagger$ & $35 \cdot 3$ \\
\hline
\end{tabular}

\footnotetext{
* Significantly different from control, $P<0.01$.

$\uparrow$ Significantly different from control, $P<0.001$.

$\ddagger$ Significantly different from value with FCCP alone, $P<0.02$.
}

\section{Uptake of radioactive phosphate}

Intracellular levels of inorganic phosphate in boar and human spermatozoa were affected by agents which may alter cyclic AMP levels (Text-fig. 1). In this experiment, the spermatozoa were allowed to accumulate radioactive phosphate for about $10 \mathrm{~min}$; the suspension was then divided into equal portions and added to tubes containing different test substances or buffer. In the 


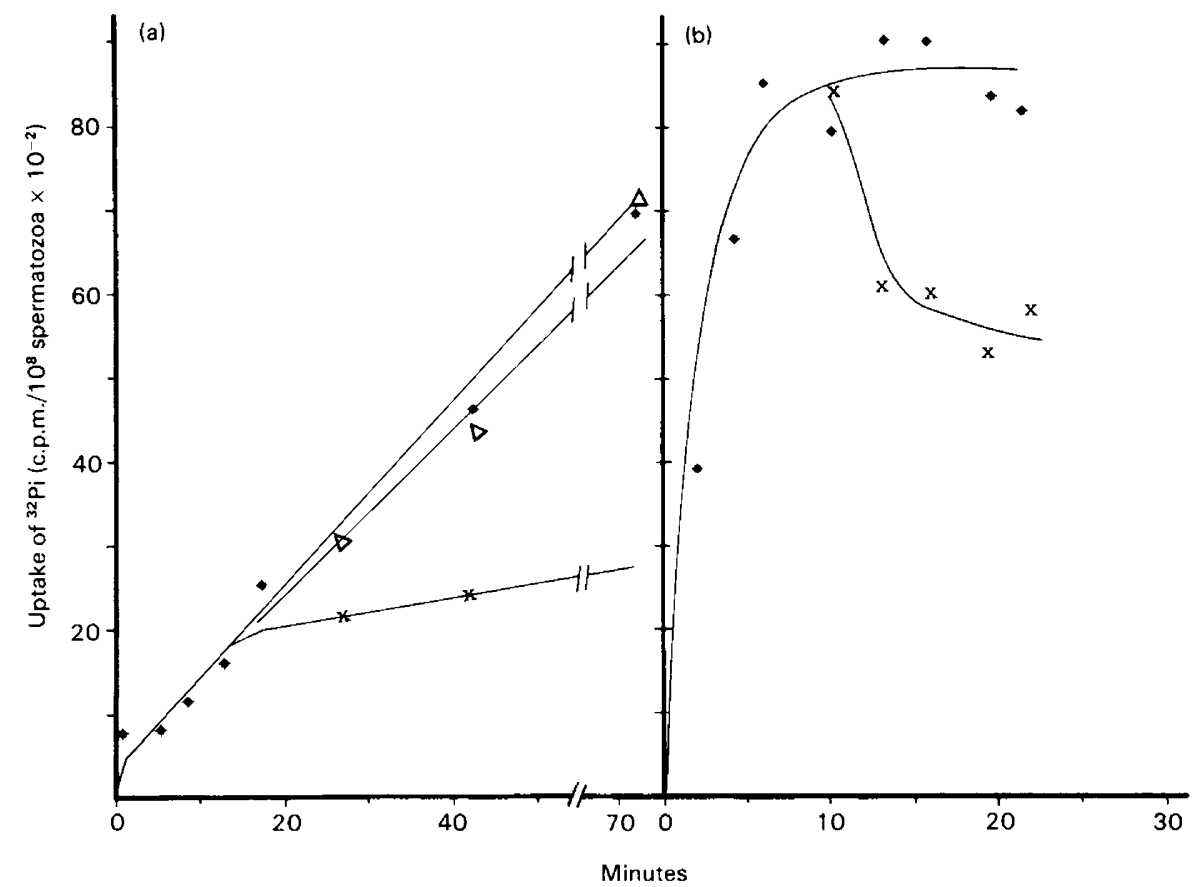

Text-fig. 1. Effect of various test substances (added $8 \mathrm{~min}$ after addition of the isotope) on the accumulation of radioactive inorganic phosphate by suspensions of washed spermatozoa. (a) Boar spermatozoa: control $(\bullet) ; 5$ mM-adenine $(\triangle) ; 8$ mM-theophylline +5 mм-dibutyryl cyclic AMP $(x)$. Tubes contained $8 \mathrm{ml}$ sperm suspension $\left(2.19 \times 10^{8}\right.$ cells $\left./ \mathrm{ml}\right)$ and $1.0 \mathrm{mM}$ ${ }^{32} \mathrm{Pi}$ (sp. act. $5 \mu \mathrm{Ci} / \mathrm{ml}$ ). (b) Human spermatozoa: control (๑); $8 \mathrm{mM}$-theophylline $+5 \mathrm{mM}$ dibutyryl cyclic AMP $(x)$. Tubes contained $1.3 \mathrm{ml}$ sperm suspension $\left(0.34 \times 10^{8}\right.$ cells $\left./ \mathrm{ml}\right)$ and $0.1 \mathrm{mM}{ }^{32} \mathrm{P}$ (sp. act. $4 \mu \mathrm{Ci} / \mathrm{ml}$ ).

experiments with boar spermatozoa, the controls continued to accumulate radioactive phosphate over the 75 -min test period. Spermatozoa treated with theophylline + dibutyryl cyclic AMP showed a markedly lower rate of accumulation. A second control included the addition of the purine analogue adenine (which does not inhibit the activity of cyclic AMP phosphodiesterase): the uptake rate was similar to that when no additions were made. Theophylline + dibutyryl cyclic AMP also reduced the rate of accumulation of inorganic phosphate by human spermatozoa although the concentration of inorganic phosphate used in this experiment was not as high as that used with boar spermatozoa, for which the availability of large numbers of spermatozoa permitted the use of lower specific activities.

When theophylline was added to the sperm suspensions before the addition of the isotope, the results were essentially the same for the spermatozoa of both species and showed that theophylline or the cyclic AMP analogue, dibutyryl cyclic AMP, reduce the amount of radioactive phosphate accumulated by cells. We also attempted to determine whether there was a significant difference in the amount of ${ }^{32} \mathrm{P}$ incorporated into acid-insoluble proteins (i.e. lipid-extracted proteins precipitated by trichloroacetic acid) in the presence and absence of theophylline and/or dibutyryl cyclic AMP. However, this fraction was less than $5 \%$ of the total radioactivity taken up by cells, and at this small level of activity no significant differences were observed.

\section{Discussion}

Huacuja et al. (1977) reported that ${ }^{33} \mathrm{P}$ is incorporated into specific proteins of the plasma membranes of human spermatozoa in the presence of cyclic $\mathrm{AMP}^{\mathrm{N}}$. We have previously presented evidence, using fluorescent membrane probes, that methylxanthines and dibutyryl cyclic AMP 
decrease the membrane potential of boar spermatozoa and also reduce divalent cation binding to the plasma membrane of human spermatozoa (Peterson \& Freund, 1971, 1976; Peterson et al., 1977). New evidence for a role for cyclic nucleotides in ion transport is presented in the present report in which it has been shown that theophylline and dibutyryl cyclic AMP inhibit the uptake of both calcium and phosphate ions in boar and human spermatozoa. The findings for calcium uptake in the presence of A23187 are consistent with and support the mechanism proposed for the effects of this ionophore on bovine spermatozoa by Babcock et al. (1976).

In the absence of exogenous calcium, or when calcium is present at low concentrations, the predominant effect of the ionophore is to short-circuit the mitochondrial membrane to calcium. This effect and reduced calcium binding to other cellular receptors, without an effect on an outwardly directed plasma membrane pump, should reduce the net inward gradient for exogenous calcium and thus reduce calcium influx. High concentrations of ionophore and calcium overwhelm both the mitochondrial and membrane pumps and allow free entry of calcium ions. The finding that theophylline + dibutyryl cyclic AMP also decrease calcium uptake by spermatozoa suggests that cyclic AMP may interact with these plasma membrane pumps. When mitochondria were de-energized by FCCP, theophylline + dibutyryl cyclic AMP were still effective in reducing calcium uptake, supporting a direct effect of cyclic AMP at the plasma membrane rather than at the mitochondrial membrane. Since increases in internal calcium appear to be detrimental to sperm motility, this action may be one mechanism by which cyclic nucleotides increase (or maintain) good motility in spermatozoa. However, these experiments do not prove that cyclic AMP acts directly on a transport process. Such proof requires the development of a method which can directly assay calcium transport, e.g. studies with isolated plasma membrane vesicles.

Our earlier conclusion that the plasma membrane of human spermatozoa is impermeable to calcium must be revised in view of the present results. However, exogenous calcium, even at high levels, does not have any marked effects on the motility and metabolism of boar and human spermatozoa. Babcock et al. (1976) suggested that radioactive calcium binds to soluble cytoplasmic components of bovine spermatozoa, and it is possible that similar components, as well as calcium binding proteins and the plasma membrane itself, act as buffers to control intracellular calcium levels. H. Rasmussen (personal communication) suggests that calcium-binding proteins associated with the plasma membrane may be involved in such buffering action in some cell types.

A buffering action of this sort may also account for the observation that high concentrations of exogenous calcium do not induce the acrosome reaction in freshly ejaculated boar spermatozoa although the reaction is readily induced in the presence of both calcium and the ionophore A23187 (Reyes, Goicoechea \& Rosado, 1977; Peterson, Russell, Bundman \& Freund, 1978). In capacitated spermatozoa, calcium readily triggers the acrosome reaction without the aid of an ionophore, indicating that some change in calcium permeability, perhaps a change in the direction of membrane pumping, occurs during capacitation. This consideration makes it apparent that transport activity may change with the life cycle of the sperm cell and that transport activity may not be uniform over the entire plasma membrane.

The decrease in ${ }^{32} \mathrm{P}$ (inorganic) uptake in sperm suspensions treated with theophylline + dibutyryl cyclic AMP may also result from a direct effect of cyclic AMP on inorganic phosphate transport at the plasma membrane, but other indirect mecharisms cannot be excluded. The decreased ATP/ADP ratio that ordinarily accompanies cyclic AMP-mediated increases in motility should also increase the intracellular level of inorganic phosphate. Control mechanisms set to regulate the phosphate potential (i.e. ATP/ADP) may restrict expansion of the phosphate pool resulting in an increase in phosphate excretion and inhibition of uptake. Here, too, direct assessment of transport will be required to resolve the question. However, our present findings suggest that elevated levels of cyclic AMP influence ion transport in boar and human spermatozoa and also suggest that these effects may play a significant role in the control of motility and metabolism. 


\section{References}

Babcock, D.F., First, N.L. \& Lardy, H.A. (1975) Transport mechanisms for succinate and phosphate localized at the plasma membrane of bovine spermatozoa. J. biol. Chem. 250, 6488-6495.

Babcock, D.F., First, N.L. \& Lardy, H.A. (1976) Action of the ionophore A23187 at the cellular level. Separation of effects at the plasma and mitochondrial membranes. J. biol. Chem. 241, 38813886.

Freund, M. \& Carol, B. (1964) Factors affecting haemocytometer counts of sperm concentration in human semen. J. Reprod. Fert. 8, 149-155.

Huacuja, L., Delgado, M., Pancardo, R.M., Merchant, H. \& Rosado, A. (1977) Cyclic AMP induced incorporation of ${ }^{33} \mathrm{Pi}$ into human spermatozoa membrane components. Biol. Reprod. 17, 86-89.

Peterson, R.N. \& Freund, M. (1968) An evaluation of the respiratory capacity of human spermatozoa. $J$. Reprod. Fert. 17, 357-372.

Peterson, R.N. \& Freund, M. (1971) ATP synthesis and oxidative metabolism in human spermatozoa. Biol. Reprod. 3, 47-54.

Peterson, R.N. \& Freund, M. (1976) Relationship between motility and the transport and binding of divalent cations to the plasma membrane of human spermatozoa. Fert. Steril 27, 1301-1307.

Peterson, R.N., Bundman, D. \& Freund, M. (1977) Measurement of boar spermatozoa membrane potentials using a fluorescent dye. J. Cell Biol. 75, 207a.

Peterson, R. N., Russell, L., Bundman, D. \& Freund, M. (1978) Effect of ionophore induced calcium uptake and dibutyrylcyclic AMP on the acrosome membrane of boar spermatozoa. Fedn Proc. Fedn Am. Socs. exp. Biol. 37, 380.

Reyes, A., Goicoechea, B. \& Rosado, A. (1977) In vitro capacitation of mammalian spermatozoa by the calcium ionophore A23187. Fert. Steril. 28, 356.

Schatzmann, J.F. \& Tschabold, M. (1971) The lanthanides $\mathrm{Ho}^{+3}$ and $\mathrm{Pr}^{+3}$ as inhibitors of calcium transport in human red cells. Experientia 27, 59-61.

Received 27 June 1978 